\title{
The Role of Moisturizers in Addressing Various Kinds of Dermatitis: A Review
}

\author{
Schandra Purnamawati, MD; Niken Indrastuti, Dr; Retno Danarti, Dr; and Tatan Saefudin, MD
}

\begin{abstract}
Moisturizer is a major component of basic daily skin care, particularly in presence of epidermal barrier alteration and reduced epidermal water content. It is an important part of a dermatologist's strategy to maintain skin health as well as treating various dermatoses which co-exist with skin dryness and are linked to impaired skin barrier function, such as in atopic disorders as well as other types of dermatitis. Mastering the knowledge regarding mechanism of action, application, dosage, adverse effects as well as specific clinical usage of moisturizers is a must for a dermatologist in order to support their use, particularly for evidence-based, therapeutic purposes. This review discusses the use of moisturizer both for skin health maintenance as well as a definitive or adjuvant therapy for many kinds of dermatitis.
\end{abstract}

Keywords: Moisturizers; Atopic dermatitis; Seborrheic dermatitis; Contact dermatitis; Nummular dermatitis

\section{What is Moisturizer?}

Interestingly, there is no consensus regarding the definition of moisturizer. This term was developed by marketers, promoting its function to moisten the skin. ${ }^{1}$ Moisturizer and emollient are often regarded as synonymous, even when occlusives and humectants are also part of it. Emmolients are mostly made up of lipids and their components, which fill intercorneocyte cluster gaps to enhance skin hydration, smoothness, softness, flexibility. Occlusives are other type of moisturizer which is mostly oil based and serve the function of maintaining skin water content by creating a hydrophobic barrier over the skin and blocking trans-epidermal water loss. The last type of moisturizers are humectants, that consist of hygroscopic substances which help the stratum corneum to absorb water by attracting water from dermis and a humid environment into the epidermis. ${ }^{2}$ The efficacy of moisturizers depends largely on proper selection and compliance to continuously use it.

\section{Why Do We Need Moisturizers?}

Healthy skin appearance is essential as flawed presentation may result in reduced self-esteem. ${ }^{3}$ Moisturizers are commonly used to reduce fine lines, smoothen and hydrate skin which may improve a patient's social life, psychological satisfaction and quality of life. ${ }^{4}$

Moreover, either normal skin or dermatoses with dry skin symptoms may both gain optimal benefit from proper utilization of moisturizers. Impression of skin dryness consist of visible and tactile changes of the skin as well as alteration in skin's sensory components, which presents as dry skin symptoms. These symptoms include dryness feeling and discomforts; consist of tightness, pain, itch, stinging, and tingling. ${ }^{5}$ Moisturizers work effectively to overcome dry skin underlying dermatoses, interrupting dry skin cycle while maintaining skin smoothness. ${ }^{6}$

Moisturizers also have several benefits aside from skin moistening. Some of the possible functions provided by moisturizers are as follows:

\section{Anti-inflammation -}

Some moisturizer components, such as glycyrrhetinic acid, palmitoyl-ethanolamine, telmesteine, Vitis vinifera, ceramide-
Corresponding Author: Schandra Purnamawati, MD, Universitas Gadjah Mada Dermatology and Venereology, Jl. Farmako Sekip Utara, Sinduadi, Mlati,

Sleman, Jogjakarta 5528I, Indonesia, Tel: +628I 3 I 770 I 232

Email: schandra_widikusumo@yahoo.com
Received: March 10,2017

Revised: October 23, 2017

Accepted: November 13, 2017

doi: $10.3121 / \mathrm{cmr} .2017 .1363$ 
dominant barrier repair lipids and filaggrin breakdown products have considerable anti-inflammation properties through various mechanism, such as blocking cyclooxygenase activity and down regulating cytokines as well as proinflammatory prostanoids production, providing soothing effect on inflamed skin, such as in dermatitis. ${ }^{1-2,4-8}$ Each substance will be further discussed later in this review.

\section{Antipruritic -}

Water-based moisturizers provides cooling effect from water evaporation on the skin surface, and some moisturizers may contains menthol as additive, which provides cooling sensation and therefore reducing itch symptoms. ${ }^{4-7}$

\section{Antimitotic -}

Mineral oils possess low-grade epidermal antimitotic properties and bring therapeutic benefit for dermatoses with increased epidermal mitotic activity such as psoriasis. ${ }^{4-6}$

\section{Wound healing -}

Hyaluronic acid has been demonstrated to promote wound healing acceleration. ${ }^{7,8}$

\section{How Do Moisturizers Work?}

The skin functions as a barrier, protecting underlying tissues from desiccation, infection, mechanical stress and chemical irritation. Impaired function leads to increasing trans-epidermal water loss associated with various kinds of dermatitis. ${ }^{9}$
Water from deeper epidermal layers moves upward to hydrate stratum corneum cells and is then lost to evaporation. Epidermal water content is essential to prevent skin dryness and maintain plasticity. ${ }^{10}$ Stratum corneum is an active membrane, described as a bricks and mortar model, where loss of intercellular lipids, forming the bilayers (eg, ceramides, cholesterol and fatty acids) will result in water barrier formation damage leading to dry skin. ${ }^{1}$

The structure of the stratum corneum is the pivotal factor in skin water flux, retention and overall moisturizing level. ${ }^{10}$ There are four key processes in stratum corneum formation and functioning: corneocyte, stratum corneum lipid, natural moisturizing factor, and desquamation. ${ }^{11}$ Corneocytes are the stratum corneum's physical barrier, contributing to elasticity when hydrated. Stratum corneum's lipid bilayers act as moisture barrier and despite preventing many chemicals entry; they are also means of entry for most topically applied substances. The natural moisturizing factor within corneocytes is a mix of hygroscopic molecules, which maintain and hold corneocyte's hydration. Fifty percent of natural moisturizing factors are amino acids originating from keratinocyte protein filaggrin, the remaining are salts, including lactates, urea, and electrolytes. natural moisturizing factor production is directly related to external humidity. In desquamation, corneodesmosomes are degraded by water-dependent

Table 1. Moisturizers mechanism of action ${ }^{1,6,9,12}$

\begin{tabular}{|c|c|c|c|c|}
\hline & Emollients & Humectants & Occlusives & Protein Rejuvenators \\
\hline $\begin{array}{l}\text { Mechanism of } \\
\text { action }\end{array}$ & $\begin{array}{l}\text { Saturated \& unsaturated } \\
\text { hydrocarbons with } \\
\text { variable length which } \\
\text { improves skin barrier } \\
\text { function, membrane } \\
\text { fluidity and cell signaling, } \\
\text { resulting in overall } \\
\text { improvement of skin } \\
\text { texture and appearance. } \\
\text { Often combined with } \\
\text { emulsifier }\end{array}$ & $\begin{array}{l}\text { Low molecular } \\
\text { substances in majority, } \\
\text { with capability to attract } \\
\text { water into stratum } \\
\text { corneum. Frequently } \\
\text { used with other } \\
\text { compounds which may } \\
\text { retain the water content }\end{array}$ & $\begin{array}{l}\text { Consist of oils and } \\
\text { waxes, forming an } \\
\text { inactive layer on the skin } \\
\text { surface to physically } \\
\text { block water evaporation } \\
\text { from the skin (trans- } \\
\text { epidermal water loss) }\end{array}$ & $\begin{array}{l}\text { Small molecular weight } \\
\text { proteins, believed to aid } \\
\text { skin rejuvenation by } \\
\text { replenishing skin's } \\
\text { essential proteins }\end{array}$ \\
\hline Indication & $\begin{array}{l}\text { Routine skin care, dry } \\
\text { and rough skin, } \\
\text { papulosquamous skin } \\
\text { disease }\end{array}$ & Xerosis, ichthyosis & $\begin{array}{l}\text { Prevention of contact } \\
\text { dermatitis, xerosis, } \\
\text { atopic dermatitis }\end{array}$ & $\begin{array}{l}\text { Photodamaged skin, skin } \\
\text { rejuvenation }\end{array}$ \\
\hline Adverse effect & Contact irritation (seldom) & Irritation (lactic acid, urea) & $\begin{array}{l}\text { Oily application, } \\
\text { cosmetically } \\
\text { disagreeable, folliculitis } \\
\text { (mineral oil), contact } \\
\text { dermatitis (lanolin), } \\
\text { acneiform eruption }\end{array}$ & Contact dermatitis \\
\hline Substance & $\begin{array}{l}\text { Fatty acids, fatty alcohols, } \\
\text { cholesterol, squalene, } \\
\text { pseudoceramides }\end{array}$ & $\begin{array}{l}\text { Urea, sorbitol, panthenol, } \\
\text { glycerol, propylene glycol, } \\
\text { hyaluronic acid, alpha } \\
\text { hydroxy acids }\end{array}$ & $\begin{array}{l}\text { Mineral oil, petroleum } \\
\text { jelly, beeswax, silicones, } \\
\text { zinc oxide }\end{array}$ & Collagen, elastin, keratin \\
\hline
\end{tabular}


hydrolytic agent, which work less efficiently in low moisture stratum corneum. Dry skin signs appear when corneocytes accumulate on skin surface (when stratum corneum has less than $10 \%$ water content) and lose its continuity. ${ }^{12}$

Moisturizers improve skin barrier repair, maintain skin's integrity and appearance by acting as humectants, emollients, and occlusives, each with its own mechanism of action. ${ }^{13}$ Moisturizers improves skin hydration and increases stratum corneum water content by directly providing water to the skin from their water phase and increasing occlusion to reduce trans-epidermal water loss, it also covers small skin fissures, provides a soothing protective film and protects skin from friction. Furthermore, moisturizer application smooths skin surface by filling spaces between partially desquamated skin flakes and restores the ability of the intercellular lipid bilayers to absorb, retain and redistribute water. Skin mechanics change thereafter as increased hydration facilitate degradation of corneodesmosomes, preventing corneocytes accumulation, while promoting its continuity. ${ }^{14}$ Loden $^{5}$ concludes that skin care products do not only stay inactively on the skin surface, but also penetrate to influence the skin's structure and function.

\section{Moisturizer Constituents and Main Types}

Moisturizer may be considered as cosmetics as well as therapeutic products when applied to overcome diseases associated with skin dryness. ${ }^{5}$ Moisturizers consist of actives and excipients (emulsifiers, antioxidants, preservatives). Recent evidences shows that actives and excipients induce prominent cutaneous effects. Some ingredients improve skin barrier function and clinical outcomes, whereas others deteriorate skin condition. For example, emulsifiers may weaken skin barrier while petrolatum provides an immediate barrier-repairing effect. ${ }^{2}$ Types of moisturizers are listed in Table 1

\section{Emollients}

Long chain saturated fatty acids (stearic, linoleic, oleic, lauric acid and fatty alcohols) are essential fatty acids examples of emollients, found naturally in wool fat, palm oil, and coconut oil, commonly used in cosmetic formulations or topical pharmaceuticals. Emollients influence skin physiology and pathology by exerting many effects on skin barrier function, such as eicosanoid production, membrane fluidity, and cell signaling, improving skin repair, and permeability, playing important role for therapeutic benefits. ${ }^{15}$ Emollients classification is showed in Table 2 .

\section{Humectants}

Many humectants also possess emollient properties. Natural moisturizing factors, consist of low molecular weight soluble hygroscopic substances mixture, play a major role for stratum corneum hydration (for example: lactic acid, pyrolidone carboxylic acid, and amino acids). ${ }^{6}$

Humectants can also enhance trans-epidermal water loss by increasing water absorption from dermis into epidermis, where it easily evaporates; therefore combination with occlusives is frequently required to help enhancing epidermal barrier function and hydration. ${ }^{9}$ Honey, sorbitol, glycerin, panthenol, urea, gelatin, hyaluronic acid, alpha hydroxy acids (glycolic acid, lactic acid, sodium pyrrolidine, carboxylic acid), propylene glycol and butylene glycol are examples of humectants.

\section{Occlusives}

Occlusives have the most significant effect when applied to dampened skin by creating hydrophobic barrier over the skin; contributing to the inter-corneocytes matrix. Occlusives diffuse into the intercellular lipid domains, contributing to their efficacy. ${ }^{9}$

Petroleum is a mineral oil source consisting of complex hydrocarbons combination. The most important materials are liquid paraffin and petrolatum. Petrolatum is the most effective classic occlusive moisturizer; a minimum concentration of $5 \%$, can reduce trans-epidermal water loss by more than $98 \%$, with 170 -times water vapor loss resistance as compared to olive oil. ${ }^{16}$

Lanolin, mineral oil and silicones (eg, dimethicone) can reduce trans-epidermal water loss by $20 \%$ to $30 \%$. Lanolin is also effective and widely used. It is secreted by sheep sebaceous glands and has a complex structure of esters, diesters, hydroxyesters of high molecular weight, lanolin alcohols, and lanolin acids. Unlike human sebum, it has no triglycerides. ${ }^{1}$ Negative effects with occlusives is unpleasant odor, potential allergenicity, and greasy consistency, making them less acceptable cosmetically. A wide range of occlusives is as shown in Table 3.

\section{Moisturizer Formulations}

Most moisturizers combine emollients, occlusives, and humectants. Occlusives and humectants combinations enhance skin's water-holding capacity. Furthermore, addition of certain emollients may improve esthetic quality and stability of moisturizer's active ingredients. ${ }^{17}$ When glycerol combines with occlusives, skin dryness will be synergistically

Table 2. Emollients classification ${ }^{1,6,9,12}$

\begin{tabular}{llll} 
Dry emollients & Fatty emollients & Astringent emollients & Protective emollients \\
\hline $\begin{array}{l}\text { Isopropyl palmitate, } \\
\text { isostearyl alcohol, decyl } \\
\text { oleate }\end{array}$ & $\begin{array}{l}\text { Propylene glycol, octyl } \\
\text { stearate, glyceryl stearate, } \\
\text { jojoba oil, castor oil }\end{array}$ & $\begin{array}{l}\text { Dimethicone, } \\
\text { cyclomethicone, octyl } \\
\text { octanoate, isopropyl } \\
\text { myristate }\end{array}$ & $\begin{array}{l}\text { Isopropyl isostearate, } \\
\text { diisopropyl dilinoleate }\end{array}$ \\
\end{tabular}


Table 3. Various types of occlusives $1,6,9,12$

\begin{tabular}{ll}
\hline Class & Examples \\
\hline Hydrocarbons & Petroleum jelly, paraffin, mineral oil, squalene, caprylic/capric triglyceride \\
Fatty acids & Stearic acid, lanolin acid \\
Fatty alcohols & Lanolin, cetyl alcohol, stearyl alcohol \\
Phospholipids & Lecithin \\
Polyhydric alcohols & Propylene glycol \\
Sterols & Cholesterol \\
Vegetable waxes & Candelilla, carnauba \\
Wax esters & Beeswax, lanolin, stearyl stearate \\
\hline
\end{tabular}

alleviated. ${ }^{18}$ The predominant formulation is cosmetic emulsions, most are lotions (oil-in-water emulsions) or creams (water-in-oil emulsions). Complex emulsions (eg, oilin-water-in-oil, oleaginous mixtures, serums, gels, sprays, and milks) are used to deliver and stabilize some active ingredients. Compliance is in accordance with consumer preferences and desired results; hence, will likely be poor if the patient is unsatisfied by the prescribed moisturizer. ${ }^{2}$

Different skin types (oily, normal, or dry), application sites and existing dermatoses are the basis for adjusting the formulas oil-water ratio, occlusives, and emollients. Ideally, dermatologists should recommend therapeutic moisturizers which are noncomedogenic, non irritative, and compatible with current therapeutic regimens. ${ }^{21}$ Variety of moisturizer formulations are listed in Table 4.

\section{Moisturizer Application Methods}

The right time and methods for moisturizers application hold the key to optimal benefits. Other than humectants and hydrophilic matrices, absorbing water from atmosphere or underlying skin layers, the more commonly used occlusive oils should be applied on moistened skin by prior showering or sponge bath. ${ }^{1,6}$ After rubbing moisturizer in both palms, it should be lightly applied along hair follicles direction. To prevent oil folliculitis from vigorous rubbing, application methods should be carefully explained to the patient.

Moisturizer distribution depends on the vehicle. Thick ointments are more evenly distributed compared to lower viscosity formulations and more volatile ingredients. Transfer of active ingredients to surrounding surfaces is easier for creams and ointments than lotions and tinctures. ${ }^{22}$ After application, ingredients may stay on the surface, absorbed into the skin, metabolized or disappear from the body by evaporation, sloughing off or by contact with other materials. After 8 hours, only $50 \%$ moisturizer remained on the skin surface. Therefore, depending on dryness severity, recommended application frequency varies between 1 and 3 times daily.

\section{Adverse Effects}

Compared to other topical drug prescriptions, moisturizers are rarely associated with health hazards, even when used on large body surface areas over a long period of time. Various discomforts associated with moisturizers are frequently encountered, as any substance may cause skin reactions in sensitive areas of some individuals.

Skin irritation, which is a sensory reaction or subjective sensation with or without signs and symptoms of inflammation, is the most frequent adverse effect. ${ }^{6}$ Table 5 lists possible adverse effects of moisturizers. By keeping them in mind, clinicians may select appropriate moisturizers to prevent unnecessary discomforts.

\section{Therapeutic Use of Moisturizers}

Moisturizers have a wide array of benefits for many dry skinassociated dermatoses. Skin dryness is induced by complex interactions between environmental and individual factors. Contributing factors includes low environmental temperature, low humidity, chemical exposures, microorganisms, aging, psychological stress, atopic dermatitis, and eczemas. ${ }^{23-25}$ This review emphasizes therapeutic use of moisturizers in various dematitis, such as atopic, seborrheic, contact, and nummular dermatitis.

\section{Moisturizer for Atopic Dermatitis}

Atopic dermatitis is a chronic skin inflammation, characterized with pruritus and skin barrier defect. Genetic mutations in the skin structural protein, filaggrin, lead to malfunction of the skin barrier leading to atopic dermatitis development and severity. These mutations hamper expression of filaggrin which is the structural protein responsible for maintaining epidermal barrier integrity as the skin's vital line of defense. Filaggrin deficiency leads to skin barrier defects allowing increased trans-epidermal water loss and facilitates exposures of environmental allergen and infective organisms through the skin leading to persistent skin inflammation. ${ }^{26}$

Due to its chronic and relapsing nature, atopic dermatitis management involves treatment and prevention of flares requiring long-term skin barrier restoration through effective patient counseling and caregiver's partnership. Moisturizers are the most important basic skin treatment for optimal atopic dermatitis recovery regardless the severity. ${ }^{27,28}$ Moisturizers can penetrate and help reorganize skin layers structure; therefore, it is recommended as a key step for atopic 
Table 4. Various kinds of moisturizer formulations ${ }^{10,19,20}$

\begin{tabular}{|c|c|c|c|c|}
\hline Classification & Lotions & Creams & Ointments & Gel \\
\hline Phase & Oil in water $(\mathrm{O} / \mathrm{W})$ & $\begin{array}{l}\text { Water in oil (W/O) } \\
\text { (hydrophobic) or O/W } \\
\text { (hydrophilic) }\end{array}$ & $\begin{array}{l}\text { W/O (hydrophobic)/ or } \\
\text { O/W (hydrophilic) }\end{array}$ & $\begin{array}{l}\text { Hydrophobic or } \\
\text { hydrophilic }\end{array}$ \\
\hline Preparation & $\begin{array}{l}\text { O/W prepared with } \\
\text { emulsifiers to } \\
\text { enhance spread } \\
\text { ability }\end{array}$ & $\begin{array}{l}\text { O/W creams are } \\
\text { prepared at elevated } \\
\text { temperature, followed } \\
\text { by reduction to room } \\
\text { temperature for internal } \\
\text { phase to solidify oil and } \\
\text { water ( } 50 \% \text { each) }\end{array}$ & $\begin{array}{l}\text { Does not contain } \\
\text { enough water to } \\
\text { separate into second } \\
\text { phase at room } \\
\text { temperature. Most } \\
\text { contain } 80 \% \text { oil and } \\
20 \% \text { water }\end{array}$ & $\begin{array}{l}\text { Has liquid phase in a } \\
\text { three dimensional } \\
\text { polymeric matrix with } \\
\text { physical or sometimes } \\
\text { chemical cross linkage } \\
\text { with appropriate gelling } \\
\text { agent }\end{array}$ \\
\hline Composition & $\begin{array}{l}\text { Oil, Water, Propylene } \\
\text { glycol }\end{array}$ & $\begin{array}{l}\text { W/O: emulsifier such } \\
\text { as monoglycerides, } \\
\text { sorbitan esters and } \\
\text { wool fat } \\
\text { O/W: emulsifying } \\
\text { agents such as sodium } \\
\text { or triethanolamine } \\
\text { soaps, sulfated fatty } \\
\text { alcohols and } \\
\text { polysorbates. When } \\
\text { necessary may be } \\
\text { combined with W/O } \\
\text { emulsifying agents }\end{array}$ & $\begin{array}{l}\text { W/O: water insoluble } \\
\text { hydrocarbons such as } \\
\text { paraffin, vegetable oil, } \\
\text { animal fats, waxes, } \\
\text { synthetic glycerides } \\
\text { and polyalkysiloxanes } \\
\text { O/W: mixtures of liquid } \\
\text { and solid polyethylene } \\
\text { glycols (macrogols) }\end{array}$ & $\begin{array}{l}\text { Hydrophobic gel (oleogel): } \\
\text { Liquid paraffin with } \\
\text { polyethylene or fatty oils } \\
\text { gelled with colloidal silica, } \\
\text { alumunium, or zinc soaps } \\
\text { Hydrophilic gel (hydrogel): } \\
\text { water, glycerol or } \\
\text { propylene glycol gelled } \\
\text { with suitable agents such } \\
\text { as tragacanth, starch, } \\
\text { derivatives of cellulose, } \\
\text { carboxy vinyl polymers } \\
\text { and magnesium/ } \\
\text { alumunium silicates }\end{array}$ \\
\hline Properties & $\begin{array}{l}\text { Non greasy, thinner, } \\
\text { easily spreads to } \\
\text { cover large areas }\end{array}$ & $\begin{array}{l}\text { Esthetic. Made of } \\
\text { heavier lipids }\end{array}$ & $\begin{array}{l}\text { Greasy, glossy look } \\
\text { following application } \\
\text { Forming skin's } \\
\text { protective layer, } \\
\text { particularly useful in } \\
\text { low humidity (<60\%) } \\
\text { environment }\end{array}$ & $\begin{array}{l}\text { Smooth finishing, non oily, } \\
\text { non comedogenic, } \\
\text { absorbs easily }\end{array}$ \\
\hline Usage & $\begin{array}{l}\text { Daytime moisturizer } \\
\text { for face and body. } \\
\text { After shave lotions, } \\
\text { for application on } \\
\text { hairy areas }\end{array}$ & $\begin{array}{l}\text { Night time moisturizers } \\
\text { for face hand, and non } \\
\text { hairy body parts } \\
\text { To use when no } \\
\text { occlusive effect is } \\
\text { required }\end{array}$ & $\begin{array}{l}\text { Particularly beneficial } \\
\text { when high degree of } \\
\text { occlusive is required; } \\
\text { Contraindicated for } \\
\text { intertriginous and } \\
\text { moisture bearing } \\
\text { areas }\end{array}$ & $\begin{array}{l}\text { To be used in } \\
\text { intertriginous areas, easily } \\
\text { absorbed, high } \\
\text { acceptability for face, non } \\
\text { comedogenic }\end{array}$ \\
\hline
\end{tabular}

O/W, oil in water; W/O, water in oil

dermatitis treatment together with avoidance of triggers and therapeutic measures to control symptoms and inflammation. However, the choice of moisturizer ingredients should be carefully considered as atopic dermatitis patients are more prone to contact dermatitis when compared to normal population..$^{9,26,29}$

Natural oils are widely used as moisturizer ingredients to treat and prevent dermatoses, such as atopic dermatitis. However, there are very limited data regarding their efficacy and safety profile. It has been suggested that oleic acid to linoleic acid ratio in natural oils determines their functions in skin hydrating and protecting effect on the skin. Positive effects are associated with high linoleic acid and low oleic acid ratios. High linoleic acid concentrations are believed to accelerate skin barrier repair and development, improving skin hydration, and ameliorate atopic dermatitis severity, making them perfect for steroid sparing. ${ }^{30-31}$ Safflower oil, sunflower seed oil, and sea buckthorn seed oil are natural oils with highest linoleic acid:oleic acid ratios. ${ }^{30}$ A recent study involving Bangladesh preterm infants reveals the excellent barrier repair and maintenance effects of sunflower seed oil, with 41 percent decreased risk for developing nosocomial 
Table 5. Possible adverse effects encountered with moisturizers ${ }^{1,7,16}$

\begin{tabular}{ll}
\hline Adverse effect & Possible causes \\
\hline Subjective irritation & $\begin{array}{l}\text { Humectants: Lactic acid, urea, preservatives such as benzoic or } \\
\text { sorbic acid }\end{array}$ \\
Irritant reactions & $\begin{array}{l}\text { Proteins in vegetable oils, urea, hydroxyl acids, propylene } \\
\text { glycols, solvents }\end{array}$ \\
Allergic contact dermatitis & $\begin{array}{l}\text { Lanolin, propylene glycols, vitamin E, Kathon CG, preservatives, } \\
\text { fragrances, sunscreens, herbal ingredients (such as tea tree oil, }\end{array}$ \\
& $\begin{array}{l}\text { olive oil, chamomile oil, aloe } \\
\text { Occlusive folliculitis }\end{array}$ \\
Photosensitivity eruptions and photomelanosis & $\begin{array}{l}\text { Petrolatum, mineral oils } \\
\text { Cosmetic acne }\end{array}$ \\
Contact urticaria & Occlusive oils used in water in oil preparations \\
Poisoning in burn patients & Preservatives such as sorbic acid, fragrances, balsam of Peru \\
Intoxication & Propylene glycol
\end{tabular}

infections compared to controls. However, olive oil, having relatively low linoleic acid:oleic acid ratio, can significantly deteriorate skin barrier by disrupting stratum corneum lipid structure and homeostasis. ${ }^{31}$ Further research regarding natural oils safety and efficacy for prevention and treatment of dermatoses is still required.

Humectants, such as $10 \%$ urea, have been shown to reduce trans-epidermal water loss in atopic patients. ${ }^{2}$ Urea also reduce skin irritation from sodium lauryl sulfate exposure in both atopic and normal skin. In mouse models of atopic dermatitis, application of glycerin-based moisturizer demonstrated a rapid hydration effect compared to untreated skin. ${ }^{32}$ Alphahydroxy acids are also effective treatment for dry skin. While lactic acid, particularly the L-isomer of lactic acid, stimulates ceramide synthesis, resulting in a higher production of stratum corneum ceramide and promoting a superior skin lipid barrier and dry skin resistance. ${ }^{9}$

Ceramides restore skin water permeability and barrier function. Recent studies suggested that low skin ceramide levels is a major etiologic factor in skin diseases, such as in atopic dermatitis. ${ }^{33}$ Stratum corneum consist of a significantly high ceramide composition (50\% from total lipids). Many evidences showed that epidermal lipid barrier recapitulation with ceramides is effective as adjunctive treatment for eczematous processes. According to Chamlin et al, ${ }^{34}$ topical mixtures of three key stratum corneum lipids consisting of ceramide, cholesterol, and free fatty acids in optimal proportions (3:1:1 molar ratio) can accelerate barrier repair following various external, acute, or sustained skin barrier disruption. Unlike non-physiologic lipid mixtures such as petrolatum, physiologic lipids (ceramides, cholesterol, and free fatty acids) can traverse both intact and disrupted stratum corneum. ${ }^{34}$ Therefore, natural or synthetic ceramides containing moisturizers are mostly recommended for atopic dermatitis. Lipophilic compounds like cholesterol and ceramides had been used in atopic dermatitis creams as they easily incorporate into liposomes, softening and smoothing skin texture. Nanoencapsulated triceramides are also being used to improve skin hydration. ${ }^{35}$

Nowadays, anti-inflammatory agents are incorporated with emollients or humectants; providing additional barrier repair and control dry skin. They are claimed as suitable for relieving mild-to-moderate atopic dermatitis, may reduce or substitute topical corticosteroids use, thus minimize side effects. ${ }^{36,37}$ Some anti-inflammatory agents added in moisturizers for atopic dermatitis are reviewed here. The use of these agents are to be carefully considered and selected for each patient, as some of them may be unsuitable for certain individuals who are allergic to these compounds.

Aloe vera has anti-inflammatory, anti-pruritic, analgesic and wound healing properties. ${ }^{38}$ It contains substances such as salicylic acid, magnesium lactate and gel polysaccharides. ${ }^{39}$ Previous study demonstrate that application of $0.1 \%, 0.25 \%$ and $0.5 \%$ of aloe vera extract for two weeks increase skin hydration, without any significant effect on trans-epidermal water loss. ${ }^{40}$

Bisabolol, extracted from chamomile (Matricaria recutita) plant, contains anti-inflammatory and anti-spasmodic substances such as sesquiterpene alcohol, chamazulene and flavinoids. The anti-inflammatory effect is attributed to cyclooxygenase and lipoxygenase inhibition. Bisabolol was also thought to play role in promoting granulation tissues for wound healing acceleration. ${ }^{41} \mathrm{~A}$ randomized, double blind clinical trial among 278 atopic dermatitis patients demonstrated that heparin and levomenol ( $\alpha$-bisabolol) formulation, applied twice daily for eight weeks significantly improve pruritus and disease symptoms. Bisabolol alone can ameliorate itching and inflammation; however, combination of these two agents showed higher efficacy. ${ }^{42}$

Shea butter is a fat derivation of Butyrospermum parkii kernels composed of five major fatty acids, including palmitic, stearic, oleic, linoleic, and arachidic acids. Stearic and oleic acids 
account for $85-90 \%$ of this fatty acids. ${ }^{43}$ It also contains triterpene acetate and cinnamate esters, demonstrating antiinflammatory and anti-tumor promoting effects. ${ }^{44}$

Glycyrrhetinic acid, a triterpenoid compound extracted from licorice root, has anti-inflammatory, antiviral and antitumor effects. Evidence demonstrated that glycyrrhetinic acid suppress surface markers and inflammatory mediators expression of lipopolysaccharide-stimulated mature dendritic cells, thereby reduce skin inflammation. ${ }^{45}$ Other extracted compound from licorice root is Glycyrrhiza inflata. Licochalcone A, its main component demonstrated inhibition of $\mathrm{T}$ cell proliferation and inflammatory cytokines production. ${ }^{46}$ Other components of Glycyrrhiza inflata includes licochalcone $\mathrm{B}$ and $\mathrm{D}$ which demonstrated antiinflammatory effects. ${ }^{47}$ Previous study involving mildmoderate atopic dermatitis children revealed that licochalcone containing formula application twice daily improve atopic dermatitis symptoms comparable to hydrocortisone lotion. Furthermore, licochalcone application site showed less relapse compared to other site, though this difference was insignificant. ${ }^{48}$ Interestingly, a randomized half-head study among scalp inflammation patients revealed that a leave-on tonic containing urea, lactate, polidocanol, and licochalcone A could ameliorate dryness, pruritus and inflammation. ${ }^{49}$

Niacinamide improve skin barrier functions by increasing epidermal ceramide and other intercellular lipid levels as well as promoting serine palmitoyltransferase upregulation. ${ }^{50}$ Furthermore, twice daily application of niacinamide formulation may reduce inflammation, decrease transepidermal water loss and increase stratum corneum thickness. ${ }^{51}$ Niacinamide also decrease trans-epidermal water loss in atopic dry skin significantly better, compared to white petrolatum. ${ }^{52}$ In randomized, controlled, comparative studies on stratum corneum integrity, niacinamide containing moisturizers application resulted in more rapid and sustained skin dryness and stratum corneum barrier improvement compared to conventional moisturizers. ${ }^{53}$

Palmitoylethanolamide is an endogenous lipid from fattyacid $\mathrm{N}$-acylethanolamine family. It resembles stratum corneum components and functions as peroxisome proliferators-activated receptor $\alpha$ agonist. $^{54}$ Thereby, palmitoylethanolamide possesses both anti-inflammatory and analgesic properties. ${ }^{55}$ A large multinational, multicenter study involving 2,456 mild to moderate severity atopic dermatitis patients demonstrated that palmitoylethanolamide containing moisturizers could improve pruritus, dryness and eczema lesion. Moreover, $56 \%$ of patients can discontinue topical corticosteroid usage. ${ }^{56}$

Zinc gluconate, is an effective treatment for many skin inflammations. Recent evidence shows that its antiinflammatory effects may target at peroxisome proliferatoractivated receptors- $\alpha$ (PPARs- $\alpha$ ), human $\beta$-defensin- 2 , and psoriasin. ${ }^{57,58}$
Several examples of nonsteroidal, noncalcineurin inhibitor agents are now available. ${ }^{59}$ MAS063DP was the first approved by the U.S. Food and Drug Administration to alleviate atopic dermatitis and allergic contact dermatitis symptoms. It is a nonsteroidal barrier repair cream, integrating glycyrrhetinic acid, Vitis vinifera extract and telmesteine in combination with shea butter (emollient) and hyaluronic acid (humectant). Some randomized, vehicle-controlled studies supported that this an effective monotherapy for pediatric and adult cases of mild to moderate atopic dermatitis..$^{59,60}$

Selection of moisturizer composition for atopic dermatitis plays a crucial role for treatment outcome as it determines whether it will strengthen or deteriorate skin barrier function. Atopic dermatitis patients are particularly vulnerable to adverse skin reactions due to impaired barrier function, with thinner stratum corneum cell layers and larger follicular pores. In the worst scenario, application of the wrong moisturizer could increase dermatitis and asthma risk. ${ }^{6}$ There is still lack of knowledge as to the necessary moisturizer ingredients to overcome the specific epidermal defect. ${ }^{13}$ Therefore, moisturizers selection in clinical practice is mainly influenced by safety, efficacy, absence of sensitizing agents and individual preference. $^{61}$

United Kingdom clinical experts developed a guidance regarding moisturizer selection for specific dry skin types in atopic dermatitis patients. For mild to moderate atopic dermatitis, occlusive emollient creams were recommended, while considering barrier thickness, lipid content variability, atopic dermatitis severity and body site. For more severe atopic dermatitis, occlusive emollient ointment was recommended; with the concern that this may reduce its acceptability. For very severe atopic dermatitis, occlusive ointment with zero water content is considered. Lastly, for pruritus, emollients with antipruritic substances were recommended. ${ }^{28}$

Recent Asian-Pacific region consensus guidelines recommend regular moisturizer application for atopic dermatitis maintenance and adjunctive therapy. It emphasized considerations of environmental humidity, climate, skin type and degree of dryness for moisturizer selection. Furthermore, atopic dermatitis duration, severity, patient age, treatment compliance, and financial resources should all also be taken into account. Other considerations include adjuvant properties, cosmetic acceptability, and product availability. ${ }^{29}$

\section{Moisturizers for Seborrheic Dermatitis}

Seborrheic dermatitis is a chronic-recurrent skin inflammatory disorder that commonly affects male adults. Onset may occur during puberty, due to cutaneous lipids abundance from increasing androgen-driven sebaceous gland development and sebum secretion. ${ }^{62}$

Seborrheic dermatitis commonly affects the scalp, face, and periauricular region. In some cases, the central chest, axillae 
and genital region are also involved. Pruritus is often present but not always found. Lesions most often appear as illdefined erythematous patches with pityriasiform scaling involving predilection sites. ${ }^{62,63}$ In some cases, a thicker, more confluent area, sometimes with oval, discoid plaques (medallion lesions), may appear.

The exact seborrheic dermatitis etiology remain unknown, several factors such as sebaceous activity, Malassezia colonization and individual susceptibility appears to contribute to seborrheic dermatitis pathogenesis. Epidermal barrier integrity; host immune response, neurogenic factors, emotional stress, and nutritional factors are several factors influencing individual susceptibility. ${ }^{63}$

Recent evidence shows strong correlation between epidermal barrier integrity and seborrheic dermatitis severity. In seborrheic dermatitis, alterations of corneodesmosomal hydrolysis and impaired lipid organization were observed that caused disruption of the desquamation process leading to aberrant barrier function. ${ }^{64}$ Electron microscopy findings detected epidermal barrier structural abnormalities in scalp dandruff, including corneocyte shape and corneodesmosomes alterations, disrupted lipid lamellar structure and intercellular Malassezia yeasts. ${ }^{64,65}$ Furthermore, dandruff patients are more reactive to scalp applications of histamine or oleic acid with higher itch perception or flaking. ${ }^{66}$ These findings indicate that disrupted epidermal barrier function plays a role in dandruff aggravation. Recent genetic studies suggest that disrupted barrier function may even directly cause seborrheic dermatitis-like conditions. ${ }^{66,67}$ Biochemical analysis further showed that scalp dandruff demonstrate alteration of $\mathrm{SC}$ protein, ceramides and free fatty acids profiles in the absence of apparent inflammation. ${ }^{67}$ These evidences emphasized the crucial role of barrier restoration and maintenance in the management of seborrheic dermatitis.

The main goals of seborrheic dermatitis therapy are to alleviate visible signs and associated symptoms of seborrheic dermatitis, particularly pruritus. Available treatment options include topical corticosteroids, topical antifungal agents, topical calcineurin inhibitors, and most recently, a nonsteroidal "device" cream. ${ }^{6,69}$

Nonsteroidal topical device cream is a water-based, fragrancefree cream approved by U.S. Food and Drug Administration as medical device to manage and relieve seborrheic dermatitis symptoms, such as itching, erythema, scaling, and pain. Nonsteroidal topical device cream is suggested to be applied on affected areas two to three times daily. The formulation won't be able to claim any individual active ingredient(s). However, ingredients which may contribute to symptoms improvement include the biocide piroctone olamine, multiple antioxidants (eg, telmesteine, tocopheryl acetate, ascorbyl tetraiso-palmitate), multiple skin conditioning agents (eg, ethylhexyl palmitate, bisabolol, shea butter, Vitis vinifera), and alglycera, composed of allantoin and glycyrrhetinic acid, the latter demonstrated anti-inflammatory quality. ${ }^{69}$

Two studies had evaluated nonsteroidal topical device cream antifungal activity. In a guinea pig model, once-daily topical application of both nonsteroidal topical device cream and ciclopirox cream for three days decreased $M$. furfur counts below quantification limit. In humans, tape stripping evaluation of Malassezia spp colony-forming units following twice-daily nonsteroidal topical device cream application for seven days to one side of the chest was compared to untreated healthy volunteers $(\mathrm{N}=10)$. At the end of the study, percentage reduction in Malassezia spp colony forming units was $94 \%$ on the treated side versus $49 \%$ on the untreated side $(\mathrm{P}=0.03)$. These studies suggest that nonsteroidal topical device cream may be effective for seborrheic dermatitis, at least partially due to reduction in Malassezia spp, with the antifungal effect likely related to the presence of piroctone olamine..$^{70,71}$

A randomized, investigator-blinded, parallel-group, multicenter, pilot study comparing safety and efficacy of nonsteroidal topical device cream $(n=38)$ versus desonide cream $0.05 \%(n=39)$ twice daily for mild-moderate facial seborrheic dermatitis in adults demonstrated significant signs and symptoms improvement following 14 and 28 days of treatment. Subjects percentage achieving "clear" or "almost clear" according to Investigator Global Assessment was 92\% in the desonide group and $85 \%$ in the nonsteroidal topical device cream group. Even when number of patients rated as "clear" at day 14 was greater in desonide (39\%) than nonsteroidal topical device cream group $(20 \%)$, in nonsteroidal topical device cream arm $71.4 \%$ of subjects who were clear at day 14 remained clear at day 28 as compared to $14.3 \%$ in the desonide $\operatorname{arm}(\mathrm{P}=0.0173) .{ }^{72}$ Despite the limited sample, this study demonstrated that response onset may be faster with topical corticosteroids in the first two weeks, but with prolonged application, both therapies have comparable efficacy. Furthermore, following lesion clearing, relapses were sooner and more frequently occurred with the topical corticosteroid treatment. Larger studies with longer follow up duration are required to further explore timing and seborrheic dermatitis relapse rate with different therapeutic agents.

For treating mild to moderate seborrheic dermatitis, a variety of nonsteroidal treatment options, including ketoconazole $2 \%$, ciclopirox $1 \%$, pimecrolimus $1 \%$, or nonsteroidal topical device cream are applied twice-daily. Many patients favorably respond to such application. For mild symptoms, many patients achieve seborrheic dermatitis relief within 1 to 4 weeks. Except pimecrolimus 1\% cream, these agents may be continued long term to prevent relapse without concerning any adverse effects. All four of these agents can be used intermittently to control milder flares with favorable speed. However, in more prominent cases with moderate-to-severe involvement, and/or symptoms, a short course of topical corticosteroids, once or twice daily for 1 to 2 weeks (depending 
on potency), in combination with a nonsteroidal agent, is a rational therapeutic choice.

Once the symptoms are controlled to a milder state or lesion clearance, usually within the first few to several days, topical corticosteroids can be ceased at once or tapered off over 1 to 2 weeks. Nonsteroidal agent should be continued for at least a few more weeks to prevent relapse. There is no single way to approach seborrheic dermatitis. Clinicians should individually modulate approaches to manage seborrheic dermatitis cases based on disease severity, response to treatment, and tendency for relapse. ${ }^{69}$

\section{Moisturizers for Contact Dermatitis}

Contact dermatitis is a common skin inflammation characterized by pruritic and erythematous skin lesions induced by contact with foreign substances. It is divided into two major groups: irritant and allergic. ${ }^{73}$

Clinical manifestation of contact dermatitis varies according to the causative allergen or irritant and the skin's affected area. Contact dermatitis usually appears as erythema and scaling with relatively well-demarcated, visible borders. The hands, face, and neck are usually involved, although it may occur in any area. Some contact dermatitis manifestations can be both allergic and irritant. Patients may complain of itching and discomfort, but some seek medical care due to the appearance of a rash. Acute cases may involve a dramatic flare with erythema, vesicles, and bullae; chronic cases may involve lichen with cracks and fissures. Patient history is crucial for diagnosis, and causative substance must be identified and avoided to resolve contact dermatitis and prevent further aggravation. ${ }^{73,74}$

Localized acute allergic contact dermatitis lesions are successfully treated with mid- or high-potency topical corticosteroids. On thinner skin areas, lower-potency topical corticosteroids are helpful to minimize the side effects. ${ }^{74}$ There are insufficient data to support the use of topical corticosteroids for irritant contact dermatitis. However, because it is difficult to distinguish clinically between allergic and irritant contact dermatitis, these agents are often used successfully for irritant contact dermatitis.

Primary prevention of irritant and allergic contact dermatitis involves avoidance of exposure to irritants and allergens. It may be accomplished by several means including substance elimination, substitution, training, and job task rotation. The use of personal protective equipment such as gloves, goggles face shields, and/or other skin protective equipment is important. ${ }^{74}$ Cotton liners under gloves can be used to enhance comfort and sweat absorption. Skin should be kept clean, dry, and as well moisturized as possible.

Patients with contact dermatitis should wash their skin using lukewarm water with mild soap and dry it gently. Soap should be removed carefully from finger web spaces as it is a surface-active agent, providing alkaline environment which is not gentle for the skin. Jewelry, including rings, could trap allergens and retain local moisture..$^{74,75}$

Emollients are a good secondary prevention measure to avoid continuous exposure. ${ }^{74}$ After-work creams should be procured in workplaces and workers should be instructed to use them regularly. Barrier creams are often recommended to prevent occupational contact dermatitis, this may also involve the use of specialized creams such as barrier creams containing quaternium-18 bentonite (organoclay) to prevent rhus dermatitis or creams containing chelators such as penta-acetic acid to prevent nickel, chrome, or copper dermatitis. ${ }^{76}$ However, Cochrane systematically reviewed that barrier creams may not have a long-term protective effect. Another reason why it shouldn't be promoted is that it may prevent workers from using more effective preventative measures. ${ }^{74}$

Frequent moisturizer application provides protection and strengthens skin barrier function. Lipid-rich moisturizers are particularly recommended to be routinely used in all contact dermatitis patients. When frequent moisturizer application is impractical to do, overnight application of a proper emollient may be recommended. ${ }^{76}$

Ointments are preferred over creams, as creams may have sensitizing preservatives and mildly irritating emulsifiers. ${ }^{77}$ Simple petroleum-based emollients are nearly as effective as emollients containing skin-related lipids, although several studies suggest that topical mixtures of key stratum corneum lipids, including ceramides, may accelerate barrier repair. ${ }^{34,78}$ Regardless of contact dermatitis type, restoration of damaged epidermal barrier and adequate skin hydration is extremely important for prevention of chronic contact dermatitis, even when all symptoms have resolved. Gutman et $\mathrm{al}^{79}$ advocate the "soak and smear" approach with mid- to high-potency topical corticosteroid ointments or emmolients application over a dampened skin following thorough skin hydration to "lock in" moisture.

Keratolytic agents such as salicylic acid or urea are helpful in hyperkeratotic dermatitis. In double-blind studies, moisturizers with urea have demonstrated reduced trans-epidermal water loss in atopic and ichthyotic patients. Urea also makes normal and atopic skin less susceptible against irritation to sodium lauryl sulphate. ${ }^{2}$ Treatments improving skin barrier function may decrease the possibility of further aggravation of contact dermatitis.

A sterol-enriched fraction from canola oil has demonstrated to ameliorate clinical signs of sodium lauryl sulphate-induced irritation, while other lipids (eg, fish oil, petrolatum, shea butter, and sunflower seed oil) had no effect on the degree of irritation. ${ }^{9}$ Loden and Andersson ${ }^{80}$ suggested that canola oil supplies the damaged skin barrier with adequate lipids for healing. Essential fatty acids (ie, linoleic and alpha-linoleic 
acids) influence skin physiology and pathology via their effects on skin barrier functions, eicosanoid production, membrane fluidity, and cell signaling. ${ }^{80}$

Squalene is the most commonly produced sebum component. It is a single oxygen quencher, protecting skin from lipid peroxidation due to ultraviolet and other ionizing radiation exposure. Although it is naturally produced by human body, production drastically slows after age thirty; causing skin dryness. ${ }^{81}$ Squalane is a saturated form of squalene, where hydrogenation has eliminated the double bonds making it oxidation resistant and good as moisturizers. An added quality of squalane is that even though it is technically oil, it is less greasy, odorless, non-comedogenic, antibacterial, and safe for sensitive skin. Moreover, it is also effective for treating skin disorders such as contact, seborrheic, or atopic dermatitis. $^{82}$

\section{Moisturizers for Nummular Dermatitis}

Nummular dermatitis (also known as nummular eczema) is an eczematous disorder with pruritic coin-shaped patches on the skin that are often mistaken for ringworm or psoriasis. Men usually get nummular dermatitis later in their life while women get it sooner. The etiology is unknown, but most patients have very dry skin, which allow epidermal breach and permeation of allergens. ${ }^{83,84}$ Local trauma, such as arthropod bites, chemicals contact, or abrasions, may precede an outbreak.

Contact dermatitis due to nickel, cobalt, or chromates may play a role in some nummular dermatitis cases. Venous insufficiency, stasis dermatitis, and edema may be related to involvement of lower extremities. ${ }^{85,86}$ Autoeczematization may account for the presence of multiple plaques. Severe, generalized nummular dermatitis has been associated with interferon and ribavirin therapy for hepatitis $\mathrm{C}$ and tumor necrosis factor inhibitors. ${ }^{87,88}$

Patients may complain of pruritic, burning or stinging eruption that usually starts on the legs within days to months. Symptoms wax and wane with winter; cold or dry climates, are exacerbated by temperature swings and may improve with sunlight, humidity exposure or moisturizer use. Lesion recurrence in previous lesion locations is frequent. Patient may reveal past history of eczema, atopic dermatitis, or dry and sensitive skin. ${ }^{85}$

Diagnosis is made by observing the characteristic round to oval erythematous plaques, particularly on the legs; however, they may occur anywhere on the trunk, hands, or feet. Lesions may start as erythematous-to-violaceous papules or vesicles, coalescing to form confluent plaques. Lesions often distributed symmetrically and size several centimeters. It may have overlying erosions from excoriation. Aggressively scratched old lesions may develop lichen simplex chronicus, often on lower legs, neck, scalp, or scrotum. Nummular dermatitis never affects the face and scalp. ${ }^{85}$
Treatments aimed at skin rehydration, epidermal lipid barrier repair, and inflammation/infection control. Modification of cleansing habits should be advised where soap is applied only to the axilla and groin. Soapless, lukewarm or cool showers, followed by moisturizers or medicated topical preparations application on damp skin may alleviate itching and rehydrate skin. Medicine application to dampened skin results in more effective penetration and faster healing. The "soak-and-smear" therapeutic regimen consists of 20-minute plain water soak followed by topical corticosteroid ointment or petrolatum application on wet skin. One study showed over $90 \%$ improvement in 27 of 28 patients with refractory chronic puritic eruptions when the regimen was properly followed. ${ }^{79}$

Wet wrap treatments are often effective, involving skin dampening with lukewarm water for 10 minutes followed by petrolatum or topical corticosteroid ointment application and 1-hour occlusion. Plastic wrap can be used for occlusion of small areas. Petrolatum application can be repeated five to six times a day while topical corticosteroid use should be carefully monitored to avoid adverse effect upon over usage.

When eruption has resolved, ongoing aggressive hydration may decrease the flares frequency, especially in dry environments. Ointments are more effective than creams due to more occlusion of skin barrier to the environment and more effective water retention in the skin. Heavy moisturizers or petrolatum applied to dampened skin are often effective. Emollients consist of bath oils, soap substitutes and moisturizing creams should be applied as often as required to alleviate itching, scaling and dryness. Emollients should also be applied on unaffected skin to overcome dryness. It may be necessary to try several different products to a find suitable one. Many people find one or more of these emollients to be effective: sorbolene, glycerine and cetomacrogol cream, white soft paraffin/liquid paraffin mix, fatty cream, as well as wool fat lotions. As nummular dermatitis often starts from minor skin injuries, skin should be carefully protected. If the hands are affected, use gloves and protective tools to ensure the skin is avoided from friction, detergents, solvents, other chemicals or excessive water exposure.

\section{Conclusion}

This paper emphasizes specific clinical considerations of moisturizers to support health worker's recommendation and promotion of appropriate moisturizer application, particularly for therapeutic purposes to alleviate symptoms from various kinds of dermatitis. These recommendations are in accord with evidence-based medicine.

\section{References}

1. Lodén M. The clinical benefit of moisturizers. J Eur Acad Dermatol Venereol. 2005;19(6):672-688, quiz 686-687.

2. Lodén M. Role of topical emollients and moisturizers in the treatment of dry skin barrier disorders. Am J Clin Dermatol. 2003;4(11):771-788. 
3. Ginsburg IH. The psychosocial impact of skin disease. An overview. Dermatol Clin. 1996;14(3):473-484.

4. Baumann L. Moisturizing Agents. In: Baumann L, editor. Cosmetic Dermatology- Principles and Practices. 1st ed. New York: Tata McGraw Hill. 2002;93-99.

5. Diana Draelos Z. Therapeutic moisturizers. Dermatol Clin. 2000;18(4):597-607.

6. Lodén M. Effect of moisturizers on epidermal barrier function. Clin Dermatol. 2012;30(3):286-296.

7. Marks R. Emollients. London: Martin Dunitz Ltd. 2002.

8. Nolan K, Marmur E. Moisturizers: Reality and the skin benefits. Dermatol Ther. 2012;25(3):229-233.

9. Kraft JN, Lynde CW. Moisturizers: what they are and a practical approach to product selection. Skin Therapy Lett. 2005;10(5):1-8.

10. Rawlings AV, Canestrari DA, Dobkowski B. Moisturizer technology versus clinical performance. Dermatol Ther. 2004;17(s1)(Suppl 1):49-56.

11. Johnson AW. Cosmeceuticals: Function and the skin barrier. In: Draelos ZD, editor. Procedures in cosmetic dermatology series: cosmeceuticals. 1st ed. Philadelphia: Elsevier. 2005; 97-102.

12. Lynde CW. Moisturizers: what they are and how they work. Skin Therapy Lett. 2001;6(13):3-5.

13. Madison KC. Barrier function of the skin: la raison dêtre of the epidermis. J Invest Dermatol. 2003;121(2):231241.

14. Jemec GB, Na R. Hydration and plasticity following long-term use of a moisturizer: a single-blind study. Acta Derm Venereol. 2002;1 82(5):322-324.

15. Mao-Qiang M, Brown BE, Wu-Pong S, Feingold KR, Elias PM. Exogenous nonphysiologic vs physiologic lipids. Divergent mechanisms for correction of permeability barrier dysfunction. Arch Dermatol. 1995;131(7):809-816.

16. Ghadially R, Halkier-Sorensen L, Elias PM. Effects of petrolatum on stratum corneum structure and function. J Am Acad Dermatol. 1992;26(3):387-396.

17. Diana Draelos Z. Therapeutic moisturizers. Dermatol Clin. 2000;18(4):597-607.

18. Summers RS, Summers B, Chandar P, Feinberg C, Gurskey R, Rawlings AV. The effect of lipids with and without humectant on skin xerosis. J Soc Cosmet Chem. 1996;47:27-39.

19. Rawlings AV, Davies A, Carlomusto M, et al. Effect of lactic acid isomers on keratinocyte ceramide synthesis, stratum corneum lipid levels and stratum corneum barrier function. Arch Dermatol Res. 1996;288(7):383390.

20. Marks R. Xerosis. In: Lebwohl MG, Heymann WR, Berth-Jones J, Coulson I, editors. Treatment of skin disease: comprehensive therapeutic strategies. 1st ed. New York: Mosby. 2002;665-667.

21. Bikowski J. The use of therapeutic moisturizers in various dermatologic disorders. Cutis. 2001;68(5) (Suppl):3-11.
22. Ivens UI, Steinkjer B, Serup J, Tetens V. Ointment is evenly spread on the skin, in contrast to creams and solutions. Br J Dermatol. 2001;145(2):264-267.

23. Ashida Y, Ogo M, Denda M. Epidermal interleukin1alpha generation is amplified at low humidity: implications for the pathogenesis of inflammatory dermatoses. Br J Dermatol. 2001;144(2):238-243.

24. Morris-Jones R, Robertson SJ, Ross JS, White IR, McFadden JP, Rycroft RJG. Dermatitis caused by physical irritants. Br J Dermatol. 2002;147(2):270-275.

25. Garg A, Chren MM, Sands LP, et al. Psychological stress perturbs epidermal permeability barrier homeostasis: implications for the pathogenesis of stress-associated skin disorders. Arch Dermatol. 2001;137(1):53-59.

26. Kabashima K. New concept of the pathogenesis of atopic dermatitis: Interplay among the barrier, allergy, and pruritus as a trinity. J Dermatol Sci. 2013;70(1):3-11.

27. Simpson E, Dutronc Y. A new body moisturizer increases skin hydration and improves atopic dermatitis symptoms among children and adults. J Drugs Dermatol. 2011;10(7):744-749.

28. Moncrieff G, Cork M, Lawton S, Kokiet S, Daly C, Clark C. Use of emollients in dry-skin conditions: consensus statement. Clin Exp Dermatol. 2013;38(3):231-238, quiz 238.

29. Rubel D, Thirumoorthy T, Soebaryo RW, et al; AsiaPacific Consensus Group for Atopic Dermatitis. Consensus guidelines for the management of atopic dermatitis: An Asia-Pacific perspective. J Dermatol. 2013;40(3):160-171.

30. Danby SG, AlEnezi T, Sultan A, et al. Effect of olive and sunflower seed oil on the adult skin barrier: implications for neonatal skin care. Pediatr Dermatol. 2013;30(1):42-50.

31. Darmstadt G, Saha S, Ahmed A, et al. Effect of topical treatment with skin barrier-enhancing emollients on nosocomial infections in preterm infants in Bangladesh: a randomised controlled trial. Lancet. 2005;365(9464):1039-1045.

32. Matsumoto K, Mizukoshi K, Oyobikawa M, Ohshima H, Sakai Y, Tagami H. Objective evaluation of the efficacy of daily topical applications of cosmetics bases using the hairless mouse model of atopic dermatitis. Skin Res Technol. 2005;11(3):209-217.

33. Choi MJ, Maibach HI. Role of ceramides in barrier function of healthy and diseased skin. Am J Clin Dermatol. 2005;6(4):215-223.

34. Chamlin SL, Kao J, Frieden IJ, et al. Ceramide-dominant barrier repair lipids alleviate childhood atopic dermatitis: Changes in barrier function provide a sensitive indicator of disease activity. J Am Acad Dermatol. 2002;47(2):198-208.

35. Lohani A, Verma A, Joshi H, Yadav N, Karki N. Nanotechnology-Based Cosmeceuticals. ISRN Dermatology; 2014: Article ID 843687. 
36. Varothai S, Nitayavardhana S, Kulthanan K. Moisturizers for patients with atopic dermatitis. Asian Pac J Allergy Immunol. 2013;31(2):91-98.

37. Paediatric Dermatology Subspecialty Core Group of the Philippine Dermatological Society. A guide to understanding moisturizers in atopic dermatitis. Quezon (PH): Philippine Dermatological Society. 2014.

38. Feily A, Namazi MR. Aloe vera in dermatology: a brief review. G Ital Dermatol Venereol. 2009;144(1):85-91.

39. Bedi MK, Shenefelt PD. Herbal therapy in dermatology. Arch Dermatol. 2002;138(2):232-242.

40. DalBelo SE, Rigo Gaspar L, Berardo Gonçalves Maia Campos PM. Moisturizing effect of cosmetic formulations containing Aloe vera extract in different concentrations assessed by skin bioengineering techniques. Skin Res Technol. 2006;12(4):241-246.

41. Shenefelt PD. Herbal Treatment for Dermatologic Disorders. In: Benzie IFF, Wachtel-Galor S, editors. Herbal Medicine: Biomolecular and Clinical Aspects. 2nd ed. Florida: Boca Raton. 2011.

42. Arenberger $\mathrm{P}$, Arenbergerová M, Drozenová $\mathrm{H}$, Hladíková M, Holcová S. Effect of topical heparin and levomenol on atopic dermatitis: a randomized fourarm, placebo-controlled, double-blind clinical study. J Eur Acad Dermatol Venereol. 2011;25(6):688-694.

43. Goreja WG. Shea Butter: The Nourishing Properties of Africa's Best-Kept Natural Beauty Secret. New York: Amazing Herb Press. 2004.

44. Akihisa T, Kojima N, Kikuchi T, et al. Antiinflammatory and chemopreventive effects of triterpene cinnamates and acetates from shea fat. J Oleo Sci. 2010;59(6):273-280.

45. Kim ME, Kim HK, Kim DH, Yoon JH, Lee JS. 18ß-Glycyrrhetinic acid from licorice root impairs dendritic cells maturation and Th1 immune responses. Immunopharmacol Immunotoxicol. 2013;35(3):329335.

46. Kolbe L, Immeyer J, Batzer J, et al. Anti-inflammatory efficacy of Licochalcone A: correlation of clinical potency and in vitro effects. Arch Dermatol Res. 2006;298(1):23-30.

47. Furusawa J, Funakoshi-Tago M, Mashino T, et al. Glycyrrhiza inflata-derived chalcones, Licochalcone A, Licochalcone B and Licochalcone D, inhibit phosphorylation of NF-KB p65 in LPS signaling pathway. Int Immunopharmacol. 2009;9(4):499-507.

48. Udompataikul M, Srisatwaja W. Comparative trial of moisturizer containing licochalcone A vs. hydrocortisone lotion in the treatment of childhood atopic dermatitis: a pilot study. J Eur Acad Dermatol Venereol. 2011;25(6):660-665.

49. Schweiger D, Baufeld C, Drescher P, et al. Efficacy of a new tonic containing urea, lactate, polidocanol, and glycyrrhiza inflata root extract in the treatment of a dry, itchy, and subclinically inflamed scalp. Skin Pharmacol Physiol. 2013;26(2):108-118.
50. Tanno O, Ota Y, Kitamura N, Katsube T, Inoue S. Nicotinamide increases biosynthesis of ceramides as well as other stratum corneum lipids to improve the epidermal permeability barrier. Br J Dermatol. 2000;143(3):524-531.

51. Mohammed D, Crowther JM, Matts PJ, Hadgraft J, Lane ME. Influence of niacinamide containing formulations on the molecular and biophysical properties of the stratum corneum. Int J Pharm. 2013;441(1-2):192-201.

52. Soma Y, Kashima M, Imaizumi A, Takahama H, Kawakami T, Mizoguchi M. Moisturizing effects of topical nicotinamide on atopic dry skin. Int J Dermatol. 2005;44(3):197-202.

53. Christman JC, Fix DK, Lucus SC, et al. Two randomized, controlled, comparative studies of the stratum corneum integrity benefits of two cosmetic niacinamide/glycerin body moisturizers vs. conventional body moisturizers. J Drugs Dermatol. 2012;11(1):22-29.

54. Kircik L. A nonsteroidal lamellar matrix cream containing palmitoylethanolamide for the treatment of atopic dermatitis. J Drugs Dermatol. 2010;9(4):334-338.

55. D’Agostino G, La Rana G, Russo R, et al. Central administration of palmitoylethanolamide reduces hyperalgesia in mice via inhibition of NF- $\mathrm{KB}$ nuclear signalling in dorsal root ganglia. Eur J Pharmacol. 2009;613(1-3):54-59.

56. Eberlein B, Eicke C, Reinhardt HW, Ring J. Adjuvant treatment of atopic eczema: assessment of an emollient containing N-palmitoylethanolamine (ATOPA study). J Eur Acad Dermatol Venereol. 2008;22(1):73-82.

57. Poiraud C, Quereux G, Knol AC, et al. Human $\beta$-defensin-2 and psoriasin, two new innate immunity targets of zinc gluconate. Eur J Dermatol. 2012;22(5):634-639.

58. Poiraud C, Quereux G, Knol AC, Allix R, Khammari A, Dreno B. Zinc gluconate is an agonist of peroxisome proliferator-activated receptor- $\alpha$ in the epidermis. Exp Dermatol. 2012;21(5):347-351.

59. Simpson EL. Atopic dermatitis: a review of topical treatment options. Curr Med Res Opin. 2010;26(3):633640.

60. Boguniewicz M, Zeichner JA, Eichenfield LF, et al. MAS063DP is effective monotherapy for mild to moderate atopic dermatitis in infants and children: a multicenter, randomized, vehicle-controlled study. J Pediatr. 2008;152(6):854-859.

61. Eichenfield LF, Tom WL, Berger TG, et al. Guidelines of care for the management of atopic dermatitis: section 2 . Management and treatment of atopic dermatitis with topical therapies. J Am Acad Dermatol. 2014;71(1):116132.

62. Gupta AK, Bluhm R, Cooper EA, Summerbell RC, Batra R. Seborrheic dermatitis. Dermatol Clin. 2003;21(3):401-412.

63. Borda LJ, Wikramanayake TC. Seborrheic Dermatitis and Dandruff: A Comprehensive Review. J Clin Investig Dermatol. 2015;3(2):10. 
64. Turner GA, Hoptroff M, Harding CR. Stratum corneum dysfunction in dandruff. Int J Cosmet Sci. 2012;34(4):298-306.

65. Schwartz JR, Cardin CW, Dawson TL. Seborrheic dermatitis and dandruff. In: Baran R, Maibach HI, editor. Textbook of Cosmetic dermatology. London: Martin Dunitz, Ltd. 2010: 230-241.

66. Harding CR, Moore AE, Rogers SJ, Meldrum H, Scott AE, McGlone FP. Dandruff: a condition characterized by decreased levels of intercellular lipids in scalp stratum corneum and impaired barrier function. Arch Dermatol Res. 2002;294(5):221-230.

67. Kerr K, Darcy T, Henry J, et al. Epidermal changes associated with symptomatic resolution of dandruff: biomarkers of scalp health. Int J Dermatol. 2011;50(1):102-113.

68. Naldi L, Rebora A. Clinical practice: seborrheic dermatitis. N Engl J Med. 2009;360(4):387-396.

69. Del Rosso JQ. Adult seborrheic dermatitis: a status report on practical topical management. J Clin Aesthet Dermatol. 2011;4(5):32-38.

70. Nalamothu V, OLeary AL, Kandavilli S, Fraser J, Pandya V. Evaluation of a nonsteroidal topical cream in a guinea pig model of Malassezia furfur infection. Clin Dermatol. 2009;27(6)(Suppl):S41-S43.

71. Kircik L. An open-label, single-center pilot study to determine the antifungal activity of a new nonsteroidal cream (Promiseb Topical Cream) after 7 days of use in healthy volunteers. Clin Dermatol. 2009;27(6) (Suppl):S44-S47.

72. Elewski B. An investigator-blind, randomized, 4-week, parallel-group, multicenter pilot study to compare the safety and efficacy of a nonsteroidal cream (Promiseb Topical Cream) and desonide cream $0.05 \%$ in the twicedaily treatment of mild to moderate seborrheic dermatitis of the face. Clin Dermatol. 2009;27(6) (Suppl):S48-S53.

73. Usatine RP. Contact dermatitis. In: Usatine RP, Smith M, Mayeaux EJ Jr, editor. Color Atlas of Family Medicine. New York: McGraw-Hill; 2009.

74. American Academy of Allergy. Asthma and Immunology; American College of Allergy, Asthma and Immunology. Contact dermatitis: a practice parameter. Ann Allergy Asthma Immunol. 2006;97(3 Suppl 2):S1-S38.

75. Lynde C, Guenther L, Diepgen TL, et al. Canadian hand dermatitis management guidelines. J Cutan Med Surg. 2010;14(6):267-284.

76. Nicholson PJ. Evidence-based guidelines: occupational contact dermatitis and urticaria. Occup Med (Chic Ill). 2010;60(7):502-504.

77. Coenraads PJ. Hand Eczema. N Engl J Med. 2012;367(19):1829-1837.

78. Kucharekova M, van de Kerkhof PCM, van der Valk PGM. A randomized comparison of an emollient containing skin-related lipids with a petrolatum-based emollient as adjunct in the treatment of chronic hand dermatitis. Contact Dermat. 2003;48(6):293-299.

79. Gutman AB, Kligman AM, Sciacca J, James WD. Soak and Smear: a standard technique revisited. Arch Dermatol. 2005;141(12):1556-1559.

80. Lodén M, Andersson AC. Effect of topically applied lipids on surfactant-irritated skin. Br J Dermatol. 1996;134(2):215-220.

81. Kelly GS. Squalene and its potential clinical uses. Altern Med Rev. 1999;4(1):29-36.

82. Wołosik K, Knaś M, Zalewska A, Niczyporuk M, Przystupa AW. The importance and perspective of plantbased squalene in cosmetology. J Cosmet Sci. 2013;64(1):59-66.

83. Aoyama H, Tanaka M, Hara M, Tabata N, Tagami H. Nummular eczema: An addition of senile xerosis and unique cutaneous reactivities to environmental aeroallergens. Dermatology. 1999; 199: 135-139.

84. Ozkaya E. Adult-onset atopic dermatitis. J Am Acad Dermatol. 2005; 52: 579-582.

85. Jiamton S, Tangjaturonrusamee C, Kulthanan K. Clinical features and aggravating factors in nummular eczema in Thais. Asian Pac J Allergy Immunol. 2013;31(1):36-42.

86. Bendl BJ. Nummular eczema of statis origin. The backbone of a morphologic pattern of diverse etiology. Int J Dermatol. 1979;18(2):129-135.

87. Shen Y, Pielop J, Hsu S. Generalized nummular eczema secondary to peginterferon Alfa-2b and ribavirin combination therapy for hepatitis $\mathrm{C}$ infection. Arch Dermatol. 2005; 141: 102-103.

88. Flendrie M, Vissers WHPM, Creemers MCW, de Jong EMGJ, van de Kerkhof PCM, van Riel PLCM. Dermatological conditions during TNF-alpha-blocking therapy in patients with rheumatoid arthritis: a prospective study. Arthritis Res Ther. 2005;7(3):R666-R676.

\section{Author Affiliations}

Schandra Purnamawati, MD*, + ; Niken Indrastuti, Dr*; Retno Danarti, Dr*; Tatan Saefudin, MD

*Department of Dermatology and Venereology, Faculty of Medicine, Universitas Gadjah Mada/ Dr. Sardjito Hospital, Yogyakarta, Indonesia

$\dagger$ Faculty of Medicine, Universitas Jenderal Soedirman, Purwokerto, Indonesia

†Politeknik Kesehatan Jakarta, Indonesia 